\title{
The Influence of Individual Determinants on Adherence to Feeding Guidelines for Infants Born to HIV Positive Mothers in Rakai District
}

\author{
Nwanna Uchechukwu Kevin \\ Faculty of Health Sciences, Victoria University Uganda, Kampala, Uganda \\ Email: uchenwanna1@gmail.com, uche4score@yahoo.com
}

How to cite this paper: Kevin, N.U. (2019) The Influence of Individual Determinants on Adherence to Feeding Guidelines for Infants Born to HIV Positive Mothers in Rakai District. World Journal of AIDS, 9 , 118-128.

https://doi.org/10.4236/wja.2019.93009

Received: July 12, 2019

Accepted: August 31, 2019

Published: September 3, 2019

Copyright $\odot 2019$ by author(s) and Scientific Research Publishing Inc. This work is licensed under the Creative Commons Attribution International License (CC BY 4.0).

http://creativecommons.org/licenses/by/4.0/

(c) (i) Open Access

\begin{abstract}
Introduction: In Uganda, Human Immunodeficiency Virus (HIV) was first reported at Kasensero landing site in Rakai district, in the South Western region in 1982. The district has continued to experience high HIV rates at $12 \%$ compared to the national average of $7.3 \%$ with relatively higher vertical transmission rates. Objective: The purpose of this study was to determine the individual determinants of adherence to feeding guidelines for infants born to HIV positive mothers in Rakai District, Uganda. Methodology: A descriptive cross-sectional study design was used with a sample size of 138 respondents and employing quantitative method of enquiry. A non-probability sampling strategy called consecutive sampling was used to sample the mothers with HIV. Data were analyzed using SPSS to generate descriptive and bivariate analysis data. Results: Individual determinants found to have a statistically significant influence to feeding guidelines for infants born to mothers living with HIV were: Age $\left(\mathrm{X}^{2}=45.967, P\right.$-value $\left.=0.000\right)$, Number of children $\left(\mathrm{X}^{2}=93.069\right.$, $P$-value $=0.000)$, Number of children given birth to since diagnosis $\left(\mathrm{X}^{2}=\right.$ 18.604, $P$-value $=0.000)$, income per month $\left(\mathrm{X}^{2}=50.477, P\right.$-value $\left.=0.000\right)$, ever had breast complication $\left(\mathrm{X}^{2}=15.039, P\right.$-value $\left.=0.000\right)$, disclosure of HIV status $\left(\mathrm{X}^{2}=10.740, P\right.$-value $\left.=0.001\right)$, quantity of breast milk produced $\left(\mathrm{X}^{2}=10.637, P\right.$-value $\left.=0.0005\right)$ and whether mothers attended antenatal care services $\left(\mathrm{X}^{2}=38.613, P\right.$-value $\left.=0.000\right)$. Conclusion: Age, Number of Children, Number of Children given birth to since diagnosis, breast complications, disclosure of HIV status, quantity of breast milk produced and utilization of antenatal care services were found to have an association with the adherence to feeding guidelines among HIV positive mother and this was statistically significant. Recommendation: General improvement of socio-economic status of the mothers should be done and be given priority so that in turn it will enable the women to adequately focus on maintaining optimum and the health
\end{abstract}


of their children.

\section{Keywords}

Rakai, Mothers, Antenatal Services, Children

\section{Introduction}

In Uganda, Human Immunodeficiency Virus (HIV) was first reported at Kasensero landing site in Rakai district, in the South Western region in 1982 (Ministry of Health, 2011; Serwadda, 1985). The district has continued to experience high HIV rates at $12 \%$ compared to the national average of $7.3 \%$ with relatively higher vertical transmission rates $(\mathrm{MOH}, 2017)$ [1].

In a longitudinal descriptive study done to examine the adherence to infant-feeding choices made by human immunodeficiency virus (HIV)-infected mothers at a Nigerian tertiary hospital, the study was conducted on mother-infant pairs recruited from the elimination of mother-to-child transmission (EMTCT) of HIV program of Nnamdi Azikiwe University Teaching Hospital, Nnewi, Nigeria. Factors found to be significantly associated with adherence to their initial choice included having individual prenatal infant-feeding counselling sessions, being married, having a small number of children, being of higher socio-economic status and the mother's educational status. However, only socio-economic status remained significant after logistic regression analysis was applied. The total MTCT of HIV rate was $1 \%$ at six months. In conclusion, the Adherence to either EFF or EBF in this study was low, owing to early breastfeeding cessation and the inability to sustain EFF (Onubogu et al., 2014) [2].

A number of studies have found that women who were financially dependent on a family member were more likely to practice mixed feeding (Desclaux et al., 2009) [3]. Other studies have in the same light reported that women who were financially independent, living within a nuclear family setting or supported by an HIV-positive partner were more likely to exclusively breastfeed (Doherty et al., 2006a) [4]; (Mataya et al., 2013) [5]. The financial vulnerability can result in nondisclosure of HIV status due to fear of stigma and lose social and/or financial support (Hofmann et al., 2009) [6]; (Fadnes et al., 2009) [7]. In a setting of non-disclosure, the practice of EBF would be a greater challenge and perhaps non-negotiable (Østergaard et al., 2010) [8]. This is even more challenging in societies where EBF is known to be a recommended feeding practice for HIV-positive mothers (Thairu et al., 2005) [9]; (Buskens et al., 2007) [10]. Conversely, HIV status disclosure to a partner and/or family members gave women the needed support to practice EBF, whilst non-disclosure was associated with the practice of mixed feeding within 6 months postpartum (Fadnes et al., 2009) [7]; (Marembo et al., 2014) [11]; (Onono et al., 2014) [12].

A number of studies suggest that women may resort to mixed feeding when 
they have concerns about insufficient breast milk, or if they perceive practising EBF to be detrimental to their own health (Kimani-Murage et al., 2011) [13]; (Østergaardet al., 2010) [8]; (Webb-Girard et al., 2012) [14]. Women who were food secure were more confident in their breast milk production and were more likely to adhere to EBF than food-insecure women (Østergaardet al., 2010) [8]; (Webb-Girard et al., 2012) [14]; (Mataya et al., 2013) [5]. In Malawi, some women believed practising EBF would improve their own feeding and health status, while other women believed EBF would be detrimental to an HIV-positive mothers' health (Kafulafula et al., 2013) [15]. In Nigeria, participants in one study believed that HIV-positive mothers might be too ill to breastfeed exclusively (Abiona et al., 2006) [16]. Studies from South Africa, Malawi and Kenya, also suggest that many women practiced mixed feeding with solids or semi-solid foods because they do not consider breast milk to be food and therefore question its nutritional value (Buskens et al., 2007) [10]; (Wachira et al., 2009) [17]; (Mataya et al., 2013) [5]. Furthermore, mixed feeding is adopted in some instances when colic is associated with hunger and inadequate breast milk (Thairu et al., 2005) [9]; (Webb-Girard et al., 2012) [14]; (Madiba et al., 2013) [18]. In some parts of Nigeria and Uganda however, breast milk is considered food, however, water is considered a necessary supplement (Abiona et al., 2006) [16]; (Fadnes et al., 2010) [7]. There were similar findings in Kenya where water is considered as "necessary for life" (Webb-Girard et al., 2012) [14]. Studies from South Africa, Burkina Faso, Cameroon, and Ethiopia all reveal that in the context of formula availability and prior knowledge of EFF as a feeding option, mothers preferred EFF due to fear of infecting their infants with HIV (Hofmann et al., 2009) [6]. When mothers perceive their breast milk as "poisonous" due to HIV infection, they wean their infants early postpartum, believing that such a practice would minimize infant exposure to HIV (Thairu et al., 2005) [9]; (Koricho et al., 2010) [19]. However, a study from Nigeria revealed a contrary finding: mothers chose EFF not for fear of HIV transmission, but because of the desire to be identified among the upper socio-economic class who could afford infant formula (Abiona et al., 2006) [16].

On the other hand, previous experience with breastfeeding, being knowledgeable about the nutritional benefits of breast milk and associating infant mortality with formula feeding influenced mothers to choose EBF (Thairu et al., 2005) [9]; (Hofmann et al., 2009) [6]. Mothers with a clear understanding on how EBF may reduce postnatal transmission were more willing to choose and adhere to the practice compared to mothers who did not have such privileged knowledge (Thairu et al., 2005) [9]; (Kafulafula et al., 2014) [15]; (Mataya et al., 2013) [5]. On the contrary, in Zambia, even though mothers understood the dangers of mixed feeding, they found it difficult to avoid the practice (Chisenga et al., 2011) [20]. Similarly, in rural settings of Namibia, Swaziland and South Africa, the lack of pre-existing cultural norms for EBF made its practice for 6 months difficult to accept and sustain (Buskens et al., 2007) [10]. 


\section{Methodology}

\subsection{Study Design}

This study design was a cross-sectional study with quantitative data collection methods. The cross-sectional study enabled the researcher to collect all the required data at a point and survey the problem in a specified period of time; the research objectives i.e. the independent and dependent variables was used to design questions that necessitated the collection and analysis of the data (Setia MS, 2016) [21].

\subsection{Study Population}

The study population was among mothers living with HIV in Rakai district. It was estimated that 1 in every 10 mothers in Rakai district are living with HIV (Rakai district Statistical Abstract, 2009) [22]. In Rakia district 23 of the health centres and two hospitals were offering services for prevention of mother to child transmission (PMTCT) (Kunihira et al., 2010) [23]. The data were collected at the 23 health centre and the two hospitals consecutively.

\subsection{Inclusion Criteria}

All HIV positive mothers living in Rakai district who are willing to participate in the study.

\subsection{Exclusion Criteria}

All HIV positive mothers living in Rakai district who were unable to answer the question due to one condition or the other.

\subsection{Sample Size Calculation}

In a study, an estimate of the number of women living with HIV in Rakia district was available, which was around 10\% (Rakai district Statistical Abstract, 2009) [22]. The researcher determined the sample size using Kishi and Leslie formula, this method is used because the actual population of a woman living with HIV in Rakia district is unavailable. This method involves the equation below:

$$
N=\frac{Z^{2} p \cdot q}{d} \quad \text { Kishi and Leslie, 1965) [24]. }
$$

where

- $n=$ desired sample size,

- $Z=$ standard normal deviate at confidence level of $95 \%$ or 1.96 ,

- $P=$ proportion in the population with (10\%),

- $Q=1-p(P$ is the proportion of the population),

- $D=$ Degree of accuracy desired at (0.05),

- $N=\frac{Z^{2} \cdot p \cdot q}{d} N=\frac{1.96^{2} \times 0.1 \times(1-0.1)}{(0.05)^{2}}$.

The $n$ value $=138$; thus, the sample size for this study is 138 . 


\subsection{Sampling Procedures}

A non-probability sampling technique called consecutive sampling technique was used to assess the woman living with HIV in Rakia district; consecutive sampling technique involves selecting all individuals who agree to participate, provided they meet pre-established criteria until the number of desired subjects is achieved. This enabled the researcher to be more assessable to the respondents and achieve the desired sample size easily. This was done at the HIV clinic and other outreaches in the district.

\subsection{Measurement of Variables}

\subsubsection{Independent Variable}

Individual determinants: Age (15 - 49 yrs.) was grouped into 15 - 19, 20 - 34 and 35 - 49. Number of Parity was grouped into 1 - 3, 4 - 6 and 7 and above. Numbers of children given birth to since diagnosis of HIV were grouped into 1, 2, 3, 4 and above. Experience of breast complications was grouped into Yes or No. Disclosure of HIV status was grouped into "Yes or No". Breast Milk production quantity was grouped into "large or average or small". Anti-natal care attendance was grouped into "Yes or No". Adherence to ART medication was grouped into "Yes or No".

\subsubsection{Dependent Variable}

Adherence to feeding guidelines for infants of HIV positive mothers: A self-question assessments method was used whereby questions about adherence were asked; the respondents were as well asked if they adhered or not.

\subsection{Data Collection and Management Methods}

\subsubsection{Quantitative Methods}

Data was collected using structured questionnaire and with the help of the research assistants. A semi-structured questionnaire was designed that contained all the questions related to the study objectives.

\subsubsection{Quantitative Analysis}

Data collected were analyzed using the Statistical Package for Social Sciences (version 22.0). Statistical calculations were done using bivariate analysis only. Some of the results were presented in charts, tables and different statistical expressions. The bivariate analysis made use of Pearson's Chi-square to establish the relationship between the independent variables and the dependent variable at an alpha level of 0.05 .

\subsection{Quality Control (Reliability and Validity)}

The following quality control measures were employed in this study:

- At analysis level, a 95\% confidence interval was used when performing bivariate and multivariate analysis.

- To ensure validity, the researcher pre-tested the questionnaires prior to data collection. 


\subsection{Ethical Considerations}

A letter of approval was sought from the research and ethics committee of Stafford University Uganda under the department of Public Health in the year 2018. The participants were assured of strict confidentiality of any information they would provide. The entire participants were treated with dignity and respect. Confidentiality and anonymity were assured to the participants by using codes for identification instead of their names. The participants were given the liberty to take part or not in the study and any attempts to opt out of this exercise will not stop them from receiving all services that they normally get.

\subsection{Limitation of the Study}

The study design (cross-sectional study) used in this study enabled us to collect the data once without follow-ups which may deprive us of some further information about the study. The researcher annulled this limitation by ensuring that the onetime data were collected justly and with proper monitoring.

\section{Results}

Out of 138 questionnaires that was distributed to the various participants in this research study, a total of 135 agreed to participate; thus making a response rate of $98 \%$.

\subsection{The Individual Determinants of Adherence to Feeding Guidelines for Infants Born to Mothers Living with HIV in Rakai District}

Age $\left(\mathrm{X}^{2}=45.967, P\right.$-value $\left.=0.000\right)$; Number of children $\left(\mathrm{X}^{2}=93.069, P\right.$-value $=$ $0.000)$; Number of children given birth to since diagnosis $\left(\mathrm{X}^{2}=18.604, P\right.$-value $=$ $0.000)$; Income per month $\left(\mathrm{X}^{2}=50.477, P\right.$-value $\left.=0.000\right)$; ever had breast complication $\left(\mathrm{X}^{2}=15.039, P\right.$-value $\left.=0.000\right)$, disclosure of HIV status $\left(\mathrm{X}^{2}=10.740\right.$, $P$-value $=0.001)$, quantity of breast milk produced $\left(\mathrm{X}^{2}=10.637, P\right.$-value $=$ $0.0005)$ and attended antenatal care services $\left(\mathrm{X}^{2}=38.613, P\right.$-value $\left.=0.000\right)$ were the individual factors found to be statistically significant with respect to adherence to feeding guidelines for infants born to mothers living with HIV in Rakai district (Table 1).

\subsection{Discussion}

The Individual Determinants of Adherence to Feeding Guidelines for Infants Born to Mothers Living with HIV in Rakai District

This research study found that Age had a statistically significant association with adherence to feeding guidelines for infants born to HIV positive in Rakai district. Age variation between mothers speaks of their maturity which may influence their adherence to feeding guidelines. This is in line with a study by Harvey, N.C., et al. (2009) [25] that found a statistically significant relationship between age and adherence to feeding guidelines. 
Table 1. Individual determinants of the respondents influencing the adherence to feeding guidelines for infants born to HIV mothers.

\begin{tabular}{|c|c|c|c|c|c|}
\hline \multirow[b]{2}{*}{ Variables } & \multicolumn{5}{|c|}{$\begin{array}{l}\text { Adherence to feeding guidelines } \\
\text { for infants born to HIV mothers }\end{array}$} \\
\hline & Categories & Adhere & Not-Adhere & $\mathrm{X}^{2}$ & $P$-value \\
\hline \multirow{3}{*}{ Age } & $15-24$ yrs & 0 & 21 & \multirow{3}{*}{45.967} & \multirow{3}{*}{0.000} \\
\hline & $25-40$ yrs & 44 & 45 & & \\
\hline & $41-49$ yrs & 25 & 0 & & \\
\hline \multirow{4}{*}{ Number of children } & $1-2$ & 0 & 53 & \multirow{4}{*}{93.069} & \multirow{4}{*}{0.000} \\
\hline & $3-4$ & 54 & 13 & & \\
\hline & $5-6$ & 15 & 0 & & \\
\hline & 7 and above & 0 & 0 & & \\
\hline \multirow{3}{*}{$\begin{array}{c}\text { Number of children } \\
\text { given birth to since } \\
\text { diagnosis }\end{array}$} & $1-3$ & 52 & 66 & \multirow{3}{*}{18.604} & \multirow{3}{*}{0.000} \\
\hline & $4-6$ & 17 & 0 & & \\
\hline & 7 and above & 0 & 0 & & \\
\hline \multirow{3}{*}{ Income per month } & Below 200,000Ugx & 0 & 35 & \multirow{3}{*}{50.477} & \multirow{3}{*}{0.000} \\
\hline & $200,000-500,000$ Ugx & 48 & 18 & & \\
\hline & Above $500,000 \mathrm{Ugx}$ & 21 & 13 & & \\
\hline \multirow{2}{*}{$\begin{array}{l}\text { Ever had breast } \\
\text { complications }\end{array}$} & Yes & 0 & 13 & \multirow{2}{*}{15.039} & \multirow{2}{*}{0.000} \\
\hline & No & 69 & 53 & & \\
\hline \multirow{2}{*}{$\begin{array}{l}\text { Disclosure of HIV } \\
\text { status }\end{array}$} & Yes & 31 & 48 & \multirow{2}{*}{10.740} & \multirow{2}{*}{0.001} \\
\hline & No & 38 & 18 & & \\
\hline \multirow{3}{*}{$\begin{array}{l}\text { Quantity of breast } \\
\text { milk produced }\end{array}$} & High & 21 & 13 & \multirow{3}{*}{10.637} & \multirow{3}{*}{0.005} \\
\hline & Average & 33 & 21 & & \\
\hline & Low & 15 & 32 & & \\
\hline \multirow{2}{*}{$\begin{array}{l}\text { Attended ante-natal } \\
\text { care service }\end{array}$} & Yes & 69 & 37 & \multirow{2}{*}{38.613} & \multirow{2}{*}{0.000} \\
\hline & No & 0 & 29 & & \\
\hline
\end{tabular}

The variables of number of children and number of children given birth to since diagnosis were also among the individual factors found to have a statistically significant association with the dependent variable i.e. adherence to feeding guidelines for infants born to HIV positive mothers. Stress from taking care of too many children may hinder adherence to breastfeeding guidelines and as well taking care of many children might have built too much confidence for the mother. This study is in line with a longitudinal descriptive study done to examine the adherence to infant-feeding choices made by Human Immunodeficiency Virus (HIV)-infected mothers at a Nigerian tertiary hospital.

Income per month was among the individual factors found to have a statistically significant association with adherence to feeding guidelines for infants born to mothers living with HIV in Rakai district. This is in line with studies that found women who were financially dependent on a family member more likely to practice mixed feeding (Desclaux et al., 2009) [3]. Other studies have in the same light reported that women who were financially independent, living within a nuclear family setting or supported by an HIV-positive partner were more likely to exclusively breastfeed (Doherty et al., 2007) [26]; (Desclaux et al., 2009) [3]; (Østergaard et al., 2010) [8] (Mataya et al., 2013) [5]. 
Ever had breast complication and disclosure of HIV status were among the individual factors found to have astatistically significant association with adherence to feeding guidelines for infants born to mothers living with HIV in Rakai district. When partners understand the health conditions of their partner they will adequately render supports to each other in achieving sustainable healthy life. This is in line with studies which reported that women who were supported by an HIV-positive partner were more likely to exclusively breastfeed (Doherty et al., 2007) [26]; (Desclaux et al., 2009) [3]; (Østergaard et al., 2010) [8]; (Mataya et al., 2013) [5]. The financial vulnerability can result in nondisclosure of HIV status due to fear of stigma and loss of social and/or financial support (Hofmann et al., 2009) [6]; (Fadnes et al., 2009) [7]. In a setting of non-disclosure, the practice of EBF would be a greater challenge and perhaps non-negotiable (Østergaard et al., 2010) [8]. This is even more challenging in societies where EBF is known to be a recommended feeding practice for HIV-positive mothers (Thairu et al., 2005) [9]; (Buskens et al., 2007) [10]. Conversely, HIV status disclosure to a partner and/or family members gave women the needed support to practice EBF, whilst non-disclosure was associated with the practice of mixed feeding within 6 months postpartum (Fadnes et al., 2009) [7]; (Marembo et al., 2014) [11]; (Onono et al., 2014) [12].

The quantity of breast milk produced had a statistically significant association with adherence to feeding guidelines for infants born to HIV positive mothers in Rakai district. The quantity of milk produced will definitely influence the choice of breastfeeding practice among mothers. The finding above is in line with the number of studies that suggest that women may resort to mixed feeding when they have concerns about insufficient breast milk, or if they perceive practicing EBF to be detrimental to their own health (Kimani-Murage et al., 2011) [13]; (Østergaard et al., 2010) [8]; (Webb-Girard et al., 2012) [14].

The variable of antenatal care services was found to have a statistically significant association with adherence to feeding guidelines. Most of the mothers who attended antenatal services will have strong knowledge about feeding guidelines and will understand how it works. This finding is reflective in a study that found that, previous experience with breastfeeding, being knowledgeable about the nutritional benefits of breast milk and associating infant mortality with formula feeding influenced mothers to choose EBF (Thairu et al., 2005) [9]; (Hofmann et al., 2009) [6]. Mothers with a clear understanding on how EBF may reduce postnatal transmission were more willing to choose and adhere to the practice compared to mothers who did not have such adequate and vital knowledge (Thairu et al., 2005) [9]; (Kafulafula et al., 2013) [15]; (Mataya et al., 2013) [5].

\section{Conclusion}

Age, Number of children, Number of children given birth to since diagnosis, Income per month, ever had breast complications, disclosure of HIV status, quantity of breast milk produced and attended antenatal care services were the individual 
factors that were found to have a statistically significant association with the dependent variable which is the adherence to feeding guidelines. The result also portrays a strong relationship between the variables that were associated with the mother's adherence to the stipulated and approved feeding guidelines.

\section{Recommendations}

General improvement of socio-economic status of the mothers should be done and be given priority so that in turn it will enable the women to adequately focus on maintaining optimum and the health of their children.

In addition to the above, proper monitoring by the health workers should be encouraged in order to follow up the practices of the mothers that are HIV positive as this will have a positive huge impact on their adherence to the feeding guidelines.

\section{Conflicts of Interest}

The author declares no conflicts of interest regarding the publication of this paper.

\section{References}

[1] Ministry of Health (2017) Uganda AIDS Indicator Survey. Ministry of Health, Kampala. https://dhsprogram.com/pubs/pdf/AIS10/AIS10.pdf

[2] Onubogu, C.U., Ugochukwu, E.F., Egbuonu, I., Azikiwe, N., Onyeka, I.N. and Onubogu, C. (2012) Adherence to Infant-Feeding Choices by HIV-Infected Mothers at a Nigerian Tertiary Hospital: The Pre-"Rapid Advice" Experience. South African Journal of Clinical Nutrition, 28, 180-186. https://doi.org/10.1080/16070658.2015.11734558

[3] Desclaux, A. and Alfieri, C. (2009). Counseling and Choosing between Infant-Feeding Options: Overall Limits and Local Interpretations by Health Care Providers and Women Living with HIV in Resource-Poor Countries (Burkina Faso, Cambodia, Cameroon). Social Science \& Medicine, 69, 821-829. https://doi.org/10.1016/j.socscimed.2009.06.007

[4] Doherty, T., Chopra, M., Nkonki, L., Jackson, D. and Greiner, T. (2006). Effect of the HIV Epidemic on Infant Feeding in South Africa: When They See Me Coming with the Tins They Laugh at Me. Bulletin of the World Health Organization, 84, 90-96. https://doi.org/10.2471/BLT.04.019448

[5] Mataya, R., Mathanga, D., Chinkhumba, J., Chibwana, A., Chikaphupha, K. and Cardiello, J. (2013) A Qualitative Study Exploring Attitudes and Perceptions of HIV Positive Women Who Stopped Breastfeeding at Six Months to Prevent Transmission of HIV to Their Children. Malawi Medical Journal, 25, 15-19.

[6] Hofmann, J., De Allegri, M., Sarker, M., Sanon, M. and Bohler, T. (2009). Breast Milk as the "Water that Supports and Preserves Life"-Socio-Cultural Constructions of Breastfeeding and Their Implications for the Elimination of Mother to Child Transmission of HIV in Sub-Saharan Africa. Health Policy, 89, 322-328. https://doi.org/10.1016/j.healthpol.2008.06.005

[7] Fadnes, L.T., Engebretsen, I.M., Wamani, H., Wangisi, J., Tumwine, J.K. and Tylleskar, T. (2009). Need to Optimise Infant Feeding Counselling: A Cross-Sectional 
Survey among HIV-Positive Mothers in Eastern Uganda. BMC Pediatrics, 9, 2. https://doi.org/10.1186/1471-2431-9-2

[8] Østergaard, L.R. and Bula, A. (2010) "They Call Our Children, Nevirapine Babies": A Qualitative Study about Exclusive Breastfeeding among HIV Positive Mothers in Malawi. African Journal of Reproductive Health, 14, 213-222.

[9] Thairu, L.N., Pelto, G.H., Rollins, N.C., Bland, R.M. and Ntshangase, N. (2005) Sociocultural Influences on Infant Feeding Decisions among HIV-Infected Women in Rural Kwa-Zulu Natal, South Africa. Maternal \& Child Nutrition, 1, 2-10. https://doi.org/10.1111/j.1740-8709.2004.00001.x

[10] Buskens, I., Jaffe, A. and Mkhatshwa, H. (2007). Infant Feeding Practices: Realities and Mindsets of Mothers in Southern Africa. AIDS Care, 19, 1101-1109. https://doi.org/10.1080/09540120701336400

[11] Marembo, J., Zvinavashe, M., Nyamakura, R., Shaibu, S. and Mogobe, K.D. (2014) Factors Influencing Infant-Feeding Choices Selected by HIV-Infected Mothers: Perspectives from Zimbabwe. Japan Journal of Nursing Science, 11, 259-267. https://doi.org/10.1111/jjns.12027

[12] Onono, M.A., Cohen, C.R., Jerop, M., Bukusi, E.A. and Turan, J.M. (2014) HIV Serostatus and Disclosure: Implications for Infant Feeding Practice in Rural South Nyanza, Kenya. BMC Public Health, 14, 390. https://doi.org/10.1186/1471-2458-14-390

[13] Kimani-Murage, E.W., Madise, N.J., Fotso, J.C., Kyobutungi, C., Mutua, M.K., Gitau, T.M. and Yatich, N. (2011) Patterns and Determinants of Breastfeeding and Complementary Feeding Practices in Urban Informal Settlements, Nairobi Kenya. BMC Public Health, 11, 396. https://doi.org/10.1186/1471-2458-11-396

[14] Webb-Girard, A., Cherobon, A., Mbugua, S., Kamau-Mbuthia, E., Amin, A. and Sellen, D.W. (2012) Food Insecurity Is Associated with Attitudes towards Exclusive Breastfeeding among Women in Urban Kenya. Maternal \& Child Nutrition, 8, 199-214. https://doi.org/10.1111/j.1740-8709.2010.00272.x

[15] Kafulafula, U.K., Hutchinson, M.K., Gennaro, S., Guttmacher, S. and Kumitawa, A. (2013) Exclusive Breastfeeding Prenatal Intentions among HIV-Positive Mothers in Blantyre, Malawi: A Correlation Study. BMC Pregnancy and Childbirth, 13, 203. https://doi.org/10.1186/1471-2393-13-203

[16] Abiona, T.C., Onayade, A.A., Ijadunola, K.T., Obiajunwa, P.O., Aina, O.I. and Thairu, L.N. (2006). Acceptability, Feasibility and Affordability of Infant Feeding options for HIV-Infected Women: A Qualitative Study in South-West Nigeria. Maternal \& Child Nutrition, 2, 135-144. https://doi.org/10.1111/j.1740-8709.2006.00050.x

[17] Wachira, J., Otieno-Nyunya, B., Ballidawa, J. and Braitstein, P. (2009). Assessment of Knowledge, Attitudes and Practices of Infant Feeding in the Context of HIV: A Case Study from Western Kenya. SAHARA-J: Journal of Social Aspects of HIVI AIDS, 6, 120-133. https://doi.org/10.1080/17290376.2009.9724940

[18] Madiba, S. and Letsoalo, R. (2013). HIV Disclosure to Partners and Family among Women Enrolled in Prevention of Mother to Child Transmission of HIV Program: Implications for Infant Feeding in Poor Resourced Communities in South Africa. Global Journal of Health Science, 5, 1. https://doi.org/10.5539/gjhs.v5n4p1

[19] Koricho, A.T., Moland, K.M. and Blystad, A. (2010). Poisonous Milk and Sinful Mothers: The Changing Meaning of Breastfeeding in the Wake of the HIV Epidemic in Addis Ababa, Ethiopia. International Breastfeeding Journal, 5, 12. https://doi.org/10.1186/1746-4358-5-12 
[20] Chisenga, M., Siame, J., Baisley, K., Kasonka, L. and Filteau, S. (2011). Determinants of Infant Feeding Choices by Zambian Mothers: A Mixed Quantitative and Qualitative Study. Maternal \& Child Nutrition, 7, 148-159. https://doi.org/10.1111/j.1740-8709.2010.00264.x

[21] Setia, M.S. (2016) Methodology Series Module 3: Cross-Sectional Studies. Indian Journal of Dermatology, 61, 261-264. https://doi.org/10.4103/0019-5154.182410

[22] Uganda Bureau of Statistics (2009) Rakai District Statistical. Abstract.

[23] Kunihira, N.R., Nuwaha, F., Mayanja, R. and Peterson, S. (2010). Barriers to Use of Antiretroviral Drugs in Rakai District of Uganda. African Health Sciences, 10, 120-129.

[24] Kish, L. (1965). Survey Sampling No. 04 HN29, K5.

[25] Harvey, N.C., Robinson, S.M., Crozier, S.R., Marriott, L.D., et al. (2009) Breast-Feeding and Adherence to Infant Feeding Guidelines Do Not Influence Bone Mass at Age 4 Years. British Journal of Nutrition, 102, 915-920. https://doi.org/10.1017/S0007114509317420

[26] Doherty, T., Chopra, M., Jackson, D., Goga, A., Colvin, M. and Persson, L.A. (2007). The Effectiveness of the WHO/UNICEF Guidelines on Infant Feeding for HIV-Positive Women: Results from a Prospective Cohort Study in South Africa. AIDS, 21, 1791-1797. https://doi.org/10.1097/QAD.0b013e32827b1462 